\title{
ANTONIO CANDIDO Y EL PROBLEMA DE LA TRADICIÓN: EL LUGAR DE OSWALD DE ANDRADE ${ }^{1}$
}

\author{
Rebeca Errázuriz Cruz \\ Universidad de Chile/Universidad de Talca \\ rebelais@gmail.com
}

RESUMEN / RESUMO / ABSTRACT

\begin{abstract}
Antonio Candido (1918) ha representado un tipo de crítica que intenta vincular la literatura latinoamericana con el contexto sociocultural de su producción. En este artículo abordaremos el pensamiento de Candido en torno a la cuestión de la tradición literaria en Brasil, asociada problemáticamente a la relación entre las influencias literarias metropolitanas, el lenguaje de las vanguardias y la creación de un sistema literario autónomo, que se alimenta de un diálogo permanente con la propia producción literaria brasileña, alcanzando un cierto grado de autonomía cultural. Para ello revisaremos un conjunto de comentarios de Candido sobre la obra narrativa de Oswald de Andrade, en las cuales dichos elementos son puestos en tensión.
\end{abstract}

Palabras Clave: Antonio Candido, Oswald de Andrade, vanguardia, modernismo brasileño, crítica brasileña.

Antonio Candido (1918) tem representado um tipo de crítica que tenta vincular a literatura latino-americana com o contexto sociocultural de sua produção. No presente artigo, abordaremos o pensamento de Candido em torno à questão da tradição literária no Brasil, associada problematicamente à relação entre as influências literárias metropolitanas, à linguagem das vanguardas e a criação de um sistema literário autônomo que se alimenta de um diálogo permanente com a própria produção literária brasileira, atingindo certo grau de autonomia cultural. Para isso, revisaremos um conjunto de comentários de Candido sobre a obra narrativa de Oswald de Andrade, em que tais elementos são postos em tensão.

1 Este artículo forma parte del proyecto FONDECYT no. 1120116 "Rebeldes, Malandros, Delincuentes y Locos: resistencias, transgresiones y expectativas utópicas en la literatura brasileña del siglo XX", del cual soy coinvestigadora. 
PalaVRas-CHaVe: Antonio Candido, Oswald de Andrade, Vanguarda, Modernismo brasileiro, Crítica brasileira.

Antonio Candido (1918) has represented a kind of criticism that attempts to associate Latin American literature with the social and cultural context of its production. In this article, we approach Candido's thoughts about the Brazilian literary tradition and how they are linked to the problematic relationship among the metropolitan literary influences, the language of the avant-gardes and the creation of an autonomous literary system - a system that is continuously nourished by the very Brazilian literary production, reaching a certain level of cultural autonomy. For this, we review a set of Candido's comments on the narrative of Oswald de Andrade, in which all these factors are displayed in a dynamic of tension.

KEYWords: Antonio Candido, Oswald de Andrade, Avant-garde, Brazilian Modernism, Brazilian Criticism.

En su ya clásica obra de 1959, Formação da Literatura brasileira, Candido afirma que ésta es una rama secundaria de la literatura portuguesa, que a su vez es un "arbusto de segunda ordem no jardim das Musas..." (11) ¿a qué se refiere con esto? Candido quiere resaltar aquí el problema que significa constituir una tradición propia para un conjunto de manifestaciones literarias que, por estar escritas en la lengua heredada de los conquistadores e impuesta durante la Colonia, parten de una situación originaria de dependencia cultural. La literatura brasileña en su origen, con las primeras obras que datan del periodo colonial, está obligada a nutrirse de una tradición que no le es propia, hasta que, a medida que se desarrolla a través del tiempo, y en constante relación con los estímulos que le brinda la propia realidad cultural de Brasil y la experiencia histórica de la cual esta realidad es portadora, logra constituirse en una tradición autónoma. De acuerdo con el autor, esto sucede cuando hay propiamente literatura y no simplemente manifestaciones literarias. La distinción entre ambos conceptos pasa por la necesidad de que las manifestaciones literarias constituyan un sistema articulado de obras que permiten ligarlas entre sí y reconocer las notas dominantes de un periodo:

Estes denominadores são, além das caraterísticas internas (língua, temas, imagens), certos elementos de natureza social e psíquica, embora literariamente organizados, que se manifestam historicamente e fazem da literatura aspecto orgânico da civilização. Entre eles se 
distinguem: a existência de um conjunto de produtores literários, mais o menos conscientes do seu papel; um conjunto de receptores, formando os diferentes tipos de público, sem os quais a obra não vive; um mecanismo transmissor, (de modo geral, uma linguagem, traduzida em estilos), que liga uns a outros (25).

Esta concepción del autor acerca de la existencia, propiamente tal, de una literatura tiene al menos dos consecuencias importantes. La primera es que Candido invierte los términos de una discusión de larga data acerca de cómo definir el carácter nacional de la literatura brasileña. El crítico, en lugar de preguntarse cuándo una literatura es brasileña y en qué elementos reconocer "lo brasileño" en una obra, se pregunta simplemente cuándo hay literatura en Brasil en tanto institución social, transformando la pregunta por lo brasileño en un falso problema a la hora de analizar la producción literaria de una nación periférica. El planteamiento de Candido resulta una suerte de giro copernicano en la usual disyuntiva entre lo local y lo cosmopolita, pues desde esta nueva perspectiva no existe una obra que pueda ser calificada más brasileña o más cosmopolita (o alienada o extranjerizante, según las perspectivas críticas de corte marxista), como dos opciones contrapuestas e irreconciliables; para el autor brasileño esta sería, en última instancia, una antinomia espuria.

La segunda consecuencia es la concepción de la literatura como fenómeno social que trasciende la mera existencia de obras, pues es necesario que exista una articulación que, si bien puede ser detectada en el puro nivel textual entre un conjunto de obras que interactúan entre sí al interior de un sistema simbólico y cuya interacción afecta y transforma constantemente sus significados, esta interacción requiere que exista algo similar -mutatis mutandis-a lo que Bourdieu llamó un campo literario, es decir, es necesario que la literatura producida en Brasil haya recorrido un camino desde la producción de obras aisladas hacia un conjunto de obras interrelacionadas. Y esto implica la existencia de un público brasileño que lee este conjunto de obras escritas en su suelo y que existe un conjunto de escritores que dialogan entre sí y crean tendencias. Por lo tanto, la literatura para Candido es más que la mera producción de textos, la literatura es entendida aquí en tanto institución social, cuya existencia parece casi natural e imperceptible en el contexto europeo pero que cobra importancia al interior de una cultura colonial o postcolonial. De ahí que Candido lo llame un fenómeno de la civilización de carácter orgánico, que vive de sus interacciones internas y en trasformación constante. 
La idea de que, desde una perspectiva histórica o diacrónica, no podamos juzgar una obra de manera individual sino solamente iluminada por la relación entre ella y el conjunto -o la tradición- al cual remite y del que se alimenta, a la vez que lo ilumina desde una perspectiva siempre renovada, sin duda hace eco de las reflexiones de T. S. Eliot en su ya famoso ensayo "La tradición y el talento individual", tal como lo nota agudamente Grínor Rojo (149). Efectivamente, ya desde 1945 y durante la década de los 50, Candido recibe una enorme influencia del new criticism, muy especialmente de Cleanth Brooks $^{2}$, quienes van a transformar profundamente su actividad crítica y fue a través de ellos que leyó la obra de T. S. Eliot, sobre quien escribió en más de una ocasión. Estas nuevas influencias, que alimentan el concepto de sistema y tradición que Candido concibe, nos permiten comprender que el proceso de formación de una literatura y de una tradición en ningún sentido constituye la creación de un canon definitivo. La intención de Candido no es escribir una historia de la literatura brasileña, ni configurar a través de ella un conjunto de textos canónicos que impliquen un sistema de inclusiones y exclusiones. Muy por el contrario, la tradición es concebida como algo orgánico y en constante movimiento, como un sistema que contiene líneas en desarrollo y tendencias incipientes que pueden o no desarrollarse ulteriormente, donde conviven tensiones y afinidades electivas en movimiento permanente, un sistema en el cual participa la producción literaria en su conjunto e incluso con independencia del valor estético de las obras en cuestión:

Quando a atividade dos escritores de um dado período se integra em tal sistema, ocorre outro elemento decisivo: a formação da continuidade literária, -espécie de transmissão da tocha entre corredores, que assegura no tempo o movimento conjunto, definindo os lineamentos de um todo. É uma tradição, no sentido completo do termo, isto é, transmissão de algo entre os homens, e o conjunto de elementos transmitidos, formando padrões que se impõem ao pensamento ou ao comportamento, e aos quais somos obrigados a nos referir, para aceitar ou rejeitar. Sem esta tradição, não há literatura, como fenómeno de civilização (Candido, Formação 25-6).

La posibilidad de generar esta tradición implica, para Candido, un doble proceso. Por una parte es necesario apropiarse de los elementos culturales 
heredados de las metrópolis, es decir, de Portugal en un primer momento, y más tarde, ya entrado el siglo XIX, de Europa occidental. Esta apropiación implica a su vez la asimilación tanto de temas como formas de escritura, géneros literarios, motivos y corrientes estéticas. Para que este proceso de apropiación pueda llevarse a cabo, es decir, para que esta asimilación no sea una mera imitación mecánica de las literaturas europeas, es fundamental que ocurra un segundo proceso de manera concomitante: que la obra del escritor se alimente de e incorpore los estímulos de la realidad brasileña. Para Candido esta dialéctica entre local y cosmopolita, tal como lo formuló en "Literatura e subdesenvolvimento"(1970), produce momentos en que prima uno u otro polo, y momentos de equilibrio entre ambos. Cuando ocurre este equilibrio, siempre transitorio, entre la apropiación de elementos literarios foráneos, puestos al servicio de la expresión de lo que podríamos llamar, siguiendo a Paulo Arantes, una experiencia de lo brasileño, estamos frente a momentos constitutivos de tradición, momentos en la historia de la literatura brasileña que se transforman en referentes para los escritores que vienen, quienes necesariamente, ya sea para continuar y profundizar o para oponerse y transformar, entrarán en diálogo con un conjunto de obras que se constituyen en acervo, en el caudal que va creando, que nutre, dilata y complejiza lo que Candido llama una tradición autónoma.

En Formação da Literatura brasileira, Candido aborda los dos primeros momentos decisivos de la literatura en Brasil, la literatura arcádica del siglo XVIII y el romanticismo del XIX, como los dos periodos que describen el proceso de su formación, la cual logra su autonomía con la obra de Machado de Assis (autor que, justamente, queda fuera del estudio que Candido realiza). La obra de Machado de Assis permitiría marcar el inicio de una tradición autónoma, es decir, de un conjunto de obras que han incorporado aspectos de los dos momentos precedentes para inaugurar por primera vez un momento de equilibrio entre elementos locales y cosmopolitas que, en su conjunción, crean un modo de expresión de la realidad brasileña. En otros ensayos, como "Literatura e cultura de 1900 a 1945" (1965), Candido identifica al modernismo brasileño, entendido en un sentido amplio que abarca desde los escritores de la Semana de Arte Moderno de 1922 hasta los ensayistas de la década del 30 como Gilberto Freyre y Sérgio Buarque de Holanda, como 
un segundo momento de equilibrio que inaugura una tradición al interior de las letras brasileñas.

Sin embargo, para Candido la constitución de una tradición no deja de contener elementos problemáticos en términos de un análisis histórico de la literatura en Brasil. El pensamiento dialéctico de Candido concibe siempre los fenómenos culturales a través de una doble faz, de modo que estos momentos de equilibrio contienen en sí aspectos que posibilitan la creación de nuevos modos de escritura que implican la maduración de una tendencia, pero también elementos de estabilización, que corren peligro de estancamiento y la repetición mecánica de estas nuevas formas de expresión literaria. Esta problemática aparece en un artículo escrito para el $\mathrm{N}^{\circ} 16$ de la revista Clima en 1944, titulado "Ordem e progresso na poesia". Allí Candido discute el fenómeno de la estabilización del modernismo.

El modernismo fue un movimiento que logró generar una tradición donde converge un conjunto de influencias ya no solo extranjeras sino también brasileñas. Sus escritores inaugurales reflexionan sobre la identidad brasileña desde una perspectiva que plantea los cruces, choques y cortocircuitos entre elementos culturales de raigambre local, como las culturas indígenas, las afrodescendientes y la economía y sociabilidad fazendeiras, con las nuevas experiencias que produce el proceso de modernización urbana y capitalista. Para expresar esta experiencia y las tensiones que se anidan en estas nuevas subjetividades, los escritores fundacionales del modernismo echan mano a los aportes literarios de las vanguardias europeas. Candido reconoce la influencia de Cendrars y Apollinaire en Mário de Andrade, la marca de António Nobre y Eugénio de Castro en Manuel Bandeira, la de Walt Whitman y Omar Khayyam en Ronald de Carvalho, y ve en estas influencias "a falta da força da nossa própria poesia, ainda incapaz de criar valores realmente transmissíveis" (Candido, "Ordem e Progresso"146).

Sin embargo, es el coraje de estos mismos escritores y su fuerza inaugural para apropiarse de las vanguardias europeas y ponerlas en diálogo con la experiencia de modernización brasileña, así como las contradicciones que este proceso genera en una cultura hacendada, lo que permite abrir nuevos caminos, que dan fruto tanto en escritores posteriores como en las obras de madurez de aquella primera generación. En el caso de los escritores posteriores, Candido ve con alegría cómo en Vinicius de Moraes aparece una encrucijada de influencias brasileñas y extranjeras, donde el poeta está ya desarrollando aspectos de la tradición abierta por el modernismo. Asimismo, esta encrucijada de influencias que entran en diálogo con la tradición modernista es visible 
también en las obras de madurez de esos mismos escritores inaugurales, que ya libres de la obnubilada fase de experimentación vanguardista y de la necesidad de ruptura que desafía los cánones ya gastados del parnasianismo, vuelven a plantearse en su obra las preguntas sobre las relaciones entre arte y sociedad, entre el individualismo exacerbado que puede producir el proceso de modernización y el vínculo con una comunidad histórica que tiene por delante la tarea de construir un futuro, donde esa modernización pueda traducirse en grados crecientes de justicia e igualdad social. Es el caso, para Candido, de la obra del último Mário de Andrade o del Carlos Drummond de Andrade de Sentimento do Mundo (1940) y A Rosa do povo (1945). Dice Candido:

Quando, porém, um Vinicius de Moraes me aparece como encruzilhada de influências brasileiras e estrangeiras, quando um Carlos Drummond consegue libertar-se de convenções passadas para encontrar a sua atitude pessoal; quando, sobretudo e finalmente, aparece toda uma geração de jovens poetas nutridos exclusivamente da atmosfera poética brasileira, estou reconhecendo a pujança daqueles mestres que se libertaram à custa de muita luta e a existência de um clima poético brasileiro. A revolução poética, operada nestes vinte anos deu os seus frutos (Candido, "Ordem e Progresso" 146).

Ahora bien, una vez que el modernismo se constituye en tradición, pese a que ello implica el camino ganado de una autonomía cultural y una retroalimentación estimulante de diálogo al interior del propio campo cultural brasileño, una tradición en literatura, y sobre todo en poesía, corre peligro, según Candido, de transformarse en convención inerte. Nuestro autor afirma que la poesía, como género, se estanca cuando se estabiliza en un orden establecido porque su progreso depende enteramente del orden en tanto algo a ser subvertido, desafiado y confrontado mediante la creación de nuevos modos de poetizar: "porque a poesia vive justamente deste ultrapassamento contínuo, que faz com que a solução de hoje ceda lugar as necesidades de evolução, porque toda ordem só tem sentido em face do progresso que vai subvertê-la" (Candido, "Ordem e Progresso"147). De modo que los momentos de orden tienen para Candido dos caras: una cara representada por el peligro del convencionalismo vacío, que ve en los jóvenes poetas que se apropian fácilmente de las innovaciones estéticas creadas por el modernismo y caen con ello en un facilismo poético, estereotipado, un virtuosismo que ya poco dice sobre el Brasil moderno en que estos poetas viven. Y la cara positiva la ve en la madurez que han adquirido los poetas inaugurales del modernismo; este es un progreso al interior de aquel 
orden, que Candido llama enriquecimiento ideológico. Con ello no quiere decir que sea necesario hacer poesía panfletaria, partidaria o de propaganda, sino que se refiere más bien la superación de una etapa de experimentalismo puro, de formalismo olvidado del contenido o tema poético, que tiende, para Candido, al solipsismo, a una poesía críptica que no habla a la comunidad ni genera formas nuevas de decir "nosotros", de comprender la experiencia de lo brasileño desde la perspectiva actual:

Uma das necessidades da poesia moderna, como já indiquei em artigo, me parece ser a reinstalação e dignificação do tema poético, combatido pelo Simbolismo e pelo Modernismo, que por aí entroncam na poesia pura. Ora, o tema requer participação ativa da inteligência, competindo ao poeta ser suficientemente vigoroso para não cair na dissertação e na poesia didática, e para criar as metáforas e os símbolos necessários à verdadeira expressão ideológica. A supressão das ideias na poesia é um preconceito como outro qualquer, e que vem em contradição com o próprio postulado de que tudo pode e deve ser objeto de poesia" (Candido, "Ordem e Progresso" 151, nota 10).

Vemos de este modo que para Candido el problema de la tradición es un fenómeno complejo y en ningún sentido homogéneo. En el caso de la literatura brasileña ocurre que, al tener un origen en una cultura ajena, los momentos de progreso que inauguran nuevos lenguajes siempre corren el riesgo de exacerbar el aspecto cosmopolita de sus influencias, interrumpiendo el diálogo con un acervo nacional y perdiendo de vista -y esto es lo central para Candido-aquello de lo cual este acervo es portador, es decir, perdiendo de vista la experiencia cultural brasileña. Pero ocurre que en los momentos de orden también se corre el peligro de debilitar una tradición literaria, al tornar convencionales los modos de expresión, los que ya no entran en contacto con la realidad brasileña, dejando de lado la reflexión y el esfuerzo que implican la búsqueda de nuevos medios de expresión que den cuenta de las vivencias actuales de una cultura.

En la medida en que el sistema literario y su tradición se fortalecen a través del tiempo, pensaríamos que estos peligros debiesen desaparecer, que la dependencia cultural ya ha sido conjurada, sin embargo una lectura atenta nos muestra que Candido siempre piensa a la cultura brasileña como un sistema constantemente amenazado por una suerte de tendencia a la precarización. Si en un momento el esfuerzo será crear modos de expresión propios que rompan con la dependencia respecto de las metrópolis, más 
adelante, ya entrada la segunda mitad del siglo XX, aparece un nuevo escenario que también corre el peligro de la precarización cultural. En el texto "Vanguarda: renovar ou permanecer", el autor brasileño afirma que en la actualidad (es decir, en 1975, año del texto) ocurre que el sistema literario brasileño está en constante amenaza de un proceso de aislamiento progresivo respecto a los estímulos que ofrecen las vivencias culturales. La llegada de la cultura de masas, de la primacía del cine y la televisión en un momento de florecimiento de la literatura brasileña, cuando existía un sistema autónomo y de gran fuerza creadora, pero inserto aún en un medio cultural donde la alfabetización es minoritaria, ha provocado que la literatura tienda a cerrarse sobre sí misma, en un elitismo lingüístico y experimental que ya no da cuenta ni entra en diálogo con las experiencias de un conjunto social y que, por lo tanto, rompe aquel triángulo del sistema literario compuesto por el circuito entre el conjunto de autores, un estilo o modo de expresión y el público, justamente porque el público se reduce a una élite cada vez más acotada y de competencias específicas: escritura para escritores y poesía para poetas. Para Candido, la creciente fragmentación y solipsismo lingüístico de la literatura es un fenómeno transversal a la cultura occidental, producto de la modernización capitalista, pero en Brasil se suma el agravante de que, a diferencia de otras naciones como las europeas, no alcanzó a consolidar el desarrollo de sus sistemas literarios. Y quizás hay un agravante aun mayor, uno que Candido probablemente no puede mencionar, pero que gravita al interior de su reflexión: el Brasil de 1975 es un Brasil que lleva ya más de diez años bajo dictadura militar.

Aquí me gustaría detenerme en un fenómeno interesante en la crítica de Candido y éste es su distancia y desconfianza constantes hacia los movimientos de vanguardia literaria. Si bien Candido ve en ellos la búsqueda de nuevos modos de decir y expresar las experiencias de un Brasil sumergido en los agitados cambios de la modernización capitalista periférica, siempre mira con cierta desconfianza el experimentalismo que tiende al solipsismo, a procesos de investigación en los aspectos formales del lenguaje que tienden a dar la espalda al diálogo con la realidad social. Candido ve en esta tendencia un peligro no solo de artificialidad, sino además de esterilización de la literatura como expresión de las vivencias sociales, quitándole justamente su cualidad de ser también ella misma un fenómeno vivo. Algo hay aquí de cierta maña que le viene de su formación de sociólogo y de su compromiso profundo con el socialismo en política, y con la necesidad de abanderarse a favor tanto de un arte como de una crítica, comprometidos con los desafíos socioculturales 
de Brasil. El empeño de Candido ha sido, desde mediados de la década de los años 40 hasta hoy, el de crear un modo de comprender la literatura que no caiga ni en la esterilidad de una crítica panfletaria, cercenadora de los procesos estéticos de experimentación que permiten que la literatura sea un modo de expresión cultural heterogéneo y plural, ni en el tecnicismo extremo, que en la fascinación obnubilada ante una teoría o un método de análisis corre el peligro de hacer desaparecer a su propio objeto, es decir, a la literatura. El camino recorrido por Candido, un camino de equilibrio inestable entre los extremos del estructuralismo, del new criticism y los de la crítica literaria marxista y el sentido que estos extremos adquirieron en el contexto de una teoría crítica latinoamericana donde ejercen una función diversa -a veces profundamente eurocéntrica- a la que ejercen en las metrópolis ha sido un proceso donde muchas veces no fue fácil comprender el sentido de ciertas obras al interior del campo cultural brasileño. Las vanguardias, de uno u otro modo, representan un límite en el pensamiento de Candido. Si bien las acepta desde un punto de vista teórico, atendiendo a su carácter innovador y a su función antropofágica, que les permite ocupar el eminente lugar dialéctico de convergencia entre lo local y lo cosmopolita, en la praxis muestra su dificultad para comprender el lugar y el valor de las vanguardias al interior de la tradición, siempre arrojadas hacia un futuro que su pensamiento no consigue vislumbrar. Un ejercicio interesante es revisar, en este sentido, la evolución de la crítica de Candido en torno a la obra narrativa de Oswald de Andrade, el famoso enfant terrible del modernismo brasileño.

III

Cuando en 1944 Oswald de Andrade publicó la primera novela de su muy anunciada trilogía Marco Zero, titulada A revolucão melancólica, Candido era el crítico literario oficial del diario Folha da Manhã y dedicó al tema tres notas: "Romance e expectativa", "Antes do Marco Zero" y "Marco Zero". En la primera de estas notas, publicada el 8 de agosto de 1943, Candido comenta la próxima aparición de tres novelas muy esperadas, entre ellas la mencionada primera parte de Marco Zero. Aquí Candido aprovecha de reflexionar acerca de la novela como género en crisis, pues es su opinión que, al fracturarse los valores de la clase burguesa, la novela como género ha entrado en una suerte de exacerbación de los valores individualistas propios de esta clase a través 
de métodos de narración que implican un volcamiento exagerado sobre las dimensiones del "yo":

\begin{abstract}
Por motivos de classe, por influência de formação social, nós temos a impressão de que atingimos um ponto mais o menos definitivo no progresso humano ao vermos a profundeza de Proust ou de Virginia Woolf; quando, muito ao contrário, o que estamos é vivendo uma ponta extrema de contradição histórica de suma ameaça para o destino do homem. Ilhar-se é perder-se. A introversão é uma morte, sobre ser uma fuga. Basta atentar para os caminhos convergentes dela e das neuroses (Candido, Folha da Manhã, 8 de ago. 1943: 7).
\end{abstract}

La opinión de Candido es que la novela ya no puede continuar por este camino -como tampoco, por cierto, por el camino de la superficialidad de la novela populista o panfletaria que oculta su dependencia de los valores burgueses- pues corre el riesgo de dar la espalda a la realidad nacional, a sus contradicciones entre los valores cosmopolitas y burgueses del Brasil del litoral y el localismo pintoresco de la literatura del interior. Es esta la posición de Candido al momento de la publicación de $A$ revolução melancólica, que vendría a ser la primera novela social de Oswald de Andrade, y que Candido esperaba como un momento de coronación y madurez de una obra narrativa que hasta el momento parecía sumamente irregular. La comparación con Mário de Andrade era inevitable, y Candido y sus compañeros de la revista Clima esperaban que la próxima obra de Oswald viniera a señalar el fin de su tendencia narrativa de corte más fragmentario, basado en la elipsis y centrado de sobremanera en experiencias subjetivas. Para Candido, esta forma fragmentaria de representación contenida en las novelas de Oswald no deja de ser una manifestación de la crisis de la sociedad burguesa, y si bien no niega los méritos estéticos del par Memórias sentimentais de João Miramar y Serafim Ponte Grande, ni las innovaciones que introduce Oswald en la literatura brasileña, con lo que Candido llama una técnica cinematográfica de narración centrada en las experiencias y la subjetividad de sus personajes centrales, aún le parece que estas novelas carecen de una visión que logre dar una imagen de lo social en cuanto totalidad, lo que para el Candido de la primera mitad de la década del 40 es un defecto. En la nota del 15 de agosto de 1943, "Antes do Marco Zero", Candido hace una revisión de la obra narrativa de Oswald, y si bien reconoce el mérito y vigor de Serafim Ponte Grande, donde se utiliza la sátira como crítica social, no deja de criticarle cierta tendencia a la superficialidad, a quedarse en el mero chiste, en los gongorismos de sus 
juegos de ingenio: "O mal do "Serafim" é o mal do sr. Oswald de Andrade: confiança excessiva no valor do dito de espírito, da piada feliz. Ora, um e outro são instrumentos, meros instrumentos que perdem a significação e o valor se erigidos em fins" (Candido, Folha da Manhã 15 de ago. 1943: 7) ${ }^{3}$.

Cuando aparece $A$ revolucão melancólica, lo que sucede según Candido es que Oswald falla al intentar pintar un fresco social mediante una técnica de narración puntillista. Celebra nuevamente las habilidades técnicas de Oswald, su ingenio y el vigor de su prosa, pero le parece que la forma de narración utilizada es inapropiada para un retrato transversal de la sociedad:

Para falar numa linguagem que lembraria a da prudência, este livro contém muita coisa boa e muita coisa ruim. Como quase tudo no mundo se poderá responder. No caso, todavia, a frase não é usada como simplificação do problema, mais como expressão muito justa da sua complexidade. O que há de bom n' A revolução melancólica é um bom sólido, definitivo, feliz. O que há de mau nela é também um mau sólido, infeliz, definitivo. Se houvesse um ritmo do bom e do mau, se interpenetrando, tudo estaria salvo e o sr. Oswald de Andrade teria feito, tal vez, uma obra prima (...). Faltou ao sr. Oswald de Andrade o golpe de mão para enfeixar as linhas que lançou e dar ao livro a inteireza das obras fortemente realizadas, onde as deficiências se tornam como que desarmonias normais num todo complexo. Neste livro é facilmente observável uma antinomia entre a concepção e a realização. O concebido, quase grandioso, tendo eu já indicado o quanto há nele de vigore de largueza. $\mathrm{O}$ realizado, não lhe correspondendo. E é esta antinomia irremediada que suprime no livro a possibilidade dialética de ultrapassar as fraquezas, vencendo-as num desenvolvimento fecundante (...) não creio que o pontilhismo seja a técnica mais indicada para os murais (Candido, Folha da Manhã 24 de oct. 1943: 7).

Las tres notas literarias publicadas el año 1943 fueron retrabajadas por Candido y publicadas en un solo artículo en su libro de 1945 Brigada ligeira, bajo el título "Estouro e libertação". Sin abandonar su posición crítica hacia $A$ revolucão melancólica, observamos en este artículo que las opiniones negativas

\footnotetext{
La crítica de Antonio Candido desató la furia de Oswald de Andrade, quien no tardó en responder a través del diario O Estado de São Paulo, el 19 de agosto de 1943, bajo el mismo título que utilizara Candido "Antes do Marco Zero". Véase Andrade 42-7. La polémica entre Candido y Oswald es analizada por Heloisa Pontes, véase Pontes 74-89.
} 
sobre Serafim Ponte Grande, Marco Zero y sobre la obra narrativa de Oswald como totalidad y aporte a la cultura brasileña se moderan considerablemente. Candido además ha tenido la oportunidad de leer Memórias sentimentais de João Miramar, que antes no había podido revisar por ser un libro de muy escasa circulación en la época, y ve en él el punto culminante de la obra de Oswald, con la invención de un personaje que constituye una suerte de Macunaima urbano y que es, según Candido, una de las obras cumbres no solo del autor sino del modernismo y la literatura brasileña en general. De Serafim Ponte Grande ya no critica la superficialidad del chiste ingenioso, sino ciertos aspectos técnicos:

Extremadamente significativo como documento intelectual, Serafim Ponte Grande é um livro falho e talvez algo fácil sob muitos aspectos, cuja técnica nos leva a pensar em comodismo estético. Parece às vezes que Oswald de Andrade refugia no estilo telegráfico e na sincopa uma certa preguiça de aprofundar os problemas de composição. Todavia, tem muito de grande livro (Candido, "Estouro" 21).

El Candido de 1945 ya no es el mismo de 1943 y deja de exigirle a la literatura una suerte de "deber ser ético y social". La crítica a Oswald ya no se centra en aspectos sociológicos, es decir, en su incapacidad de representar una totalidad social o en su apego a los valores de una clase social en crisis. Este es un Candido que ha comenzado a estudiar los trabajos del new criticism y que retrocede en sus tendencias más sociologizantes para concentrarse cada vez más en los aspectos técnicos, estructurales y estéticos como punto de partida de toda crítica literaria. Es este el año que comienza a trabajar para el Diário de São Paulo y en su primera nota para este medio, titulada "Começando", hace una clara exposición de la transformación de su postura. Nos cuenta cómo antaño había optado por una crítica que él llama "funcional" y que intentaba enlazar las obras literarias con los demás fenómenos de la cultura. Esta posición de juventud, que Candido adoptó en tiempos de gran agitación política, se basaba en la creencia de que su compromiso de izquierda era incompatible con la actitud crítica de aquellos que optaban por una posición estética abstracta, excesivamente ajena a la realidad. Un sujeto políticamente comprometido no podía abrazar una posición de tal indiferencia ni divagar en los deleites estéticos de una torre de marfil mientras -en palabras de Candido- "Roma ardía" (Candido, "Começando" 41). Y, sin embargo, el proceso de maduración de su pensamiento y sus reflexiones más recientes habían transformado aquella postura juvenil. La creencia de que un crítico políticamente comprometido debía necesariamente optar por una crítica sociologizante y en cierta medida 
contingente era un error y aquel error consistía, según Candido, en mezclar el contenido de una obra, es decir, su dimensión ideológica, con las formas de expresión que la literatura construye para manifestar su contenido, es decir, con su dimensión estética. Y en esta nota literaria de prensa, Candido expone la necesidad de defender una postura crítica de cuño estético, pues a su juicio la crítica sociológica atenta contra el arte mismo al imponer una censura sobre ciertos contenidos con independencia de la calidad de la obra, lo cual terminaría por ahogar toda producción artística:

Isto posto, é possível passar ao debate do conteúdo ideológico e tomar posição ante ele, numa segunda fase, útil, sem dúvida, mas não necessária. O julgamento deve partir da análise e apreciação da maneira (literária) por que o autor exprimiu o conteúdo (ideológico, entre outros). O que não é possível é inverter a ordem, fazendo, no julgamento, o valor literário da maneira depender da natureza do conteúdo ideológico" (Candido, "Começando" 42).

Esta evolución en el pensamiento de Candido, que implica responder al desafío de crear una crítica de cuño estético, pero al mismo tiempo capaz de vincular el análisis formal con procesos culturales y sociales más amplios, con un modo de rastrear en esas formas de arte y en sus modos de expresión una experiencia de lo brasileño, modificará profundamente su visión respecto de la obra narrativa de Oswald. En el artículo de 1970, "Disgressão sentimental sobre Oswald de Andrade", si bien Candido no modifica su opinión sobre Marco Zero, su criterio para argumentar el porqué de las fallas de esta obra se ha transformado completamente, así como su visión general de la obra narrativa de Oswald y su lugar al interior de la tradición literaria de Brasil. En primer lugar vuelve a afirmar que el gran error de composición de Marco Zero está en la combinación no resuelta entre el estilo puntillista para recrear distintos sectores y subjetividades sociales, y la voluntad de hacer una novela social que pretendía pintar un momento histórico a través del gran panorama de una totalidad social. Sin embargo, Candido opina esta vez que le parece que el camino de Oswald debió haber sido la intensificación de su técnica puntillista, abandonando la voluntad de representar una totalidad coherente, pues el gran aporte de Andrade fue, al interior de la literatura brasileña, la creación de esta técnica de narración discontinua, sincopada, subjetiva y elíptica, donde el humor y la sátira son una pieza fundamental. Al intentar volverse un "escritor serio", bajo la presión de un periodo en el que la novela social comienza a ocupar un lugar central en el campo cultural 
literario -por el momento político que se vive luego de la Revolución del 30 y con la dictadura populista de Getúlio Vargas-, Oswald trata de superar aquel papel de bromista y payaso de la burguesía y con ello se pierde, según Candido, lo mejor de su escritura, que está en Memórias sentimentais de João Miramar y Serafim Ponte Grande. De paso, Candido aprovecha de reparar la critica que hiciera en 1945 a Serafim Ponte Grande, que había tachado de superficial, y reconoce ahora la grandeza de esta obra que sitúa junto a Memórias sentimentais como la cumbre de la obra narrativa de Oswald. Candido se refiere aquí a un prejuicio de aquella época que, basado en el principio de unidad de composición de Aristóteles, lo llevó a rechazar como inválido el procedimiento discontinuo de las técnicas narrativas de Andrade. Candido cree ahora que ese es justamente el gran aporte de Andrade, que a través de esta técnica traza las subjetividades de personajes que por la vía del exceso, de los choques que expresan en su actuar y en sus impresiones, que siempre contienen algo de grotesco, de obsceno y desmedido, producen -al igual que sucede con Macunaima pero en un contexto urbano- una suerte de caída de ciertos efectos de represión y enmascaramiento burgueses que logran contravenir una visión hegemónica de la historia de manera mucho más efectiva que cualquier técnica de narración de un realismo social forzado.

De modo que es Oswald quien abre, al interior de la literatura brasileña, un modo de expresar la experiencia de Brasil a través de la representación de estas subjetividades excesivas, que aúnan en su interior las contradicciones propias de una élite donde conviven tendencias cosmopolitas con el primitivismo más salvaje. La representación de este mundo subjetivo con sus líneas de tensión rompe, según Candido, ese equilibrio machadiano mediante una técnica de choque donde Oswald combina vanguardia estética y su propia experiencia de burgués rebelde tornándola una de las tradiciones más ricas de la literatura en Brasil.

Podemos convenir entonces, a través de este recorrido, que el concepto de tradición de Candido y sus modos de concebir los entronques y estabilizaciones de diversa índole entre lo local y lo cosmopolita no está exento de tensiones internas, no necesariamente visibles en su total significación, incluso para el crítico. El punto ciego de Candido respecto de las vanguardias literarias y su tendencia hacia la experimentación verbal procede no tanto de su posible raigambre europea, sino de su tendencia al solipsismo respecto de la realidad brasileña, de su alejamiento o renuncia frente a la necesidad de habérselas con esa realidad. La necesidad de configurar formas expresivas de la experiencia brasileña no debe ser confundida con una imposición temática, 
con la necesidad de hablar de ciertos temas propiamente brasileños o locales, como ya afirmamos más arriba, sino con crear formas de expresión que den cuenta de la experiencia brasileña en términos más bien estructurales, como afirmará Candido en su madurez, con artículos como el ya clásico "Dialética da malandragem". Le interesa a Candido ese proceso a través del cual lo externo deviene interno: la transformación de la experiencia en formas verbales.

La experimentación verbal puede conducir, desde un punto de vista diacrónico, al hallazgo de nuevas formas o estructuras que expresen el devenir de la experiencia brasileña, tal como Candido logra ver en la obra de Oswald. Tuvo que esperar hasta 1970 para comprender ese lugar de Oswald - específicamente de su obra narrativa- en la tradición y su carácter fecundante, pues fue justamente en la década del sesenta que la obra de Oswald adquirió nueva vida, abriendo una nueva línea al interior de la tradición brasileña que alimentó la obra de los concretistas y los tropicalistas, cuestión que Candido menciona en una entrevista de 1974 para la revista Trans/form/ação ${ }^{4}$. Sin embargo, en aquella misma época Candido expresa sus reservas frente a la obra de los herederos de la tradición abierta por Oswald, los poetas concretos. Estas reservas no constituyen una condena estética, sino que son más bien la expresión de su preocupación ante las posibilidades de estancamiento de la tradición en la medida en que, según las palabras del mismo Candido, la vanguardia no está hecha para permanecer, sino para alumbrar nuevas formas de expresar la experiencia (Candido, "Vanguarda: renovar ou permanecer" 222).

La objeción de Candido, en este caso, no está dirigida contra la vanguardia misma, ni siquiera contra su tendencia al solipsismo -o, al menos, no principalmente-, sino a la permanencia de la misma. Candido teme que, en un afán de alejamiento de los procesos miméticos para encontrar nuevas formas de poiesis, la vanguardia termine por ahogar la posibilidad misma de la creación, encerrada en el mecanicismo fascinante de su propia descomposición. No es capaz de vislumbrar una posibilidad mimética en esa poíesis pura. Esta preocupación legítima, que para Candido constituye una constatación de lo que ocurre en la literatura brasileña y occidental durante la década de los 70 y que relaciona con la creciente fragmentación y con el imperio de lo provisorio como experiencias fundamentales de la vida en el contexto de un capitalismo tardío; bien puede haberse disipado más tarde cuando ese furor vanguardista que parecía apuntar hacia su propio vaciamiento terminó por

4 Véase Candido, "Entrevista com Antonio Candido de Mello e Souza" 11-2. 
ceder. Candido es consciente de esa posibilidad de ceguera y simplemente advierte los peligros de una permanencia de la vanguardia que termine por descomponer su relación con toda tradición. Sin embargo, la vanguardia, pese a su carácter problemático y, como todo en el pensamiento de Candido, tiene siempre una doble faz; su exacerbación, aunque contenga el peligro de la estabilización de un orden que puede devenir estéril, también puede alumbrar nuevas formas de expresión que aún no somos capaces de entrever, y esa esperanza en la fuerza de la propia literatura nunca es abandonada. En las palabras del mismo Candido:

A criatividade exige freqüentemente a produção de textos densos, que resistem à compreensão imediata e obrigam a um esforço redobrado, que constitui enriquecimento para quem o faz. Neste sentido tais textos representam uma luta contra o automatismo, que é a praga maior de toda criação. E não esqueça que o obscuro de hoje é o claro de amanhã (Candido, "Vanguarda: renovar ou permanecer" 225).

\section{BIBLIOGRAFÍA}

Andrade, Oswald. “Antes do Marco Zero". Obras completas, vol. 5. Ponta de Lança. Rio de Janeiro: Editora Civilização Brasileira. (1971): 42-7. Impreso.

Arantes, Paulo Eduardo. Sentimento da dialética na experiência intelectual brasileira. Dialética e dualidade segundo Antonio Candido e Roberto Schwarz. Rio de Janeiro: Paz e Terra, 1992. Impreso.

Candido, Antonio. "Romance e expectativa". Folha da Manhã, 8 de ago. (1943): 7. Impreso. “Antes do Marco Zero". Folha da Manhã, 15 de ago. (1943): 7. Impreso.

"Marco Zero". Folha da Manhã, 24 de oct. (1943): 7. Impreso.

"Começando". Textos de intervenção. Seleção, apresentações e notas de Vinicius Dantas. São Paulo: Duas Cidades; Editora 34 (2002): 37-44. Impreso.

"Ordem e Progresso na poesia". Textos de intervenção. Seleção, apresentações e notas de Vinicius Dantas. São Paulo: Duas Cidades; Editora 34 (2002): 143-152. Impreso.

"Vanguarda: renovar ou permanecer". Textos de intervenção. Seleção, apresentações e notas de Vinicius Dantas. São Paulo: Duas Cidades; Editora 34 (2002): 214-225. Impreso.

"Digressão sentimental sobre Oswald de Andrade". Vários escritos. Rio de Janeiro: Ouro sobre Azul (2004): 33-62.

"Estouro e libertação". Brigada ligeira. Rio de Janeiro: Ouro sobre Azul (2004): 11-28. Impreso.

"Literatura e subdesenvolvimento". A educação pela noite. Rio de Janeiro: Ouro sobre Azul (2006): 169-196. Impreso. 
Formação da literatura brasileira. Momentos decisivos. São Paulo: FAPESP; Rio de Janeiro: Ouro sobre Azul, 2009. Impreso.

"Literatura e cultura de 1900 a 1945". Literatura e sociedade. Rio de Janeiro: Ouro sobre Azul (2010): 117-146. Impreso.

"Entrevista com Antonio Candido de Mello e Souza”. Transformação vol. 34. Edição especial (2011): 3-13. Impreso.

Chalmers, Vera "O fio da meada: um estudo da crítica de Antonio Candido sobre Oswald de Andrade". Dentro do texto, dentro da vida. Ensaios sobre Antonio Candido. Maria Angela D'Incao y Eloísa Faria Scarabôtolo (Orgs.). São Paulo: Companhia das Letras; Instituto Moreira Salles (1992): 218-228. Impreso.

Eliot, T. S. "La tradición y el talento individual". Ensayos Escogidos. México D. F.: UNAM (2000): 17-29.

Pedrosa, Célia "Os dois gumes da história". Dentro do texto, dentro da vida. Ensaios sobre Antonio Candido. Maria Angela D'Incao y Eloísa Faria Scarabôtolo (Orgs.). São Paulo: Companhia das Letras; Instituto Moreira Salles (1992): 129-34. Impreso.

Pontes, Heloisa Destinos mistos. Os críticos do Grupo Clima em São Paulo. São Paulo: Companhia das Letras, 1998. Impreso.

Rojo, Grínor. De las más altas cumbres. Teoría crítica latinoamericana moderna (1876-2006). Santiago de Chile: LOM, 2012.

Ruedas de la Serna, Jorge “Antonio Candido: Cómo y por qué escribí Formação da literatura brasileira". Revista Casa de las Américas 268, julio-septiembre (2012): 117-28. 